ARTICLE HISTORY: Received: January 4, 2021 Accepted: February 25, 2021 Published: March 3, 2021

\title{
FORMATION OF STUDENTS ' LEADERSHIP SKILLS IN FOREIGN LANGUAGE CLASSES AT A NON-LINGUISTIC UNIVERSITY
}

\author{
Uvarov Valerii I. \\ Assistant Professor, Department of Foreign Languages, \\ Russian State University for the Humanities, \\ Moscow, Russia

\section{ФОРМИРОВАНИЕ ЛИДЕРСКИХ КАЧЕСТВ У СТУДЕНТОВ НА ЗАНЯТИЯХ ПО ИНОСТРАННОМУ ЯЗЫКУ В НЕЯЗЫКОВОМ ВУЗЕ}

\author{
Уваров Валерий Игоревич \\ старший преподаватель кафедры иностранных языков \\ ФГБОУ ВО «Российский государственный гуманитарный университет», \\ Москва, Россия
}

\begin{abstract}
The article makes an attempt to justify the need for the formation of leadership qualities in students of various fields of training within a non-linguistic university. The author divides the factors contributing to the solution of this problem into two categories: the personal and professional qualities of the teacher, as well as the actual set of educational activities. The author pays special attention to the usefulness of creative group types of students' activities and the use of global game technology. In conclusion, the author expresses the hope that future generations of specialists in various professional fields, being taught to be leaders, will significantly improve the world community.

Аннотация. В статье предпринимается попытка обосновать необходимость формирования лидерских качеств у студентов различных направлений подготовки в рамках неязыкового вуза. Автор подразделяет факторы, способствующие решению этой задачи на две категории: личностные и профессиональные качества преподавателя, а также актуальный набор учебных видов деятельности. Особое внимание автор уделяет полезности творческих групповых видов работы студентов и применению технологии глобальной игры. В заключении автор выражает надежду на то, что будущие поколения специалистов в различных профессиональных областях, наученные быть лидерами, существенно улучшат мировое сообщество.

Key words: leadership skills; foreign language; effectiveness; motivation; teacher's role; team work

Ключевые слова: лидерские качества; иностранный язык; эффективность; мотивация; роль преподавателя; групповая работа
\end{abstract}

\section{Введение}

Современное общество представляет собой сложный механизм, непрерывно меняющийся и усложняющийся. При этом темпы развития мирового сообщества в целом неуклонно растут с каждым годом, создавая ощутимое социальное напряжение в виде конкуренции во всех областях жизнедеятельности. Каждому общественному объединению, не зависимо от его масштабов, - от государства до малого бизнеса - требуются сильные харизматичные личности, не только обладающие всеми необходимыми компетенциями для того, чтобы вести свой коллектив к успеху, но и могущие сперва собрать и сплотить людей вокруг себя. Чем крупнее масштаб, тем сложнее становится эта задача. Однако, принимая во внимание, что любая социальная структура строится из более мелких подструктур, которые, в свою очередь, также дробятся вплоть до самой малой, имеет смысл говорить о крайней важности формирования лидерских качеств у управленцев самых низших инстанций и, за счет их карьерного роста, продвигать идеи лидерства вверх по иерархической лестнице.

По мнению автора, формировать в человеке лидерские качества можно и нужно с самого начала его сознательной жизни и на протяжении всей последующей социальной активности. При этом одним из наиболее важных этапов, подходящих для сознательного восприятия идеи лидерства и сопряженной с ним понятием ответственности, является время обучения в вузе, когда студент начинает более уверено видеть свой будущий жизненный путь и окончательно определяется с выбором профессиональной ориентации. Последнее обстоятельство является крайне важным, так как лидеры нужны во всех профессиональных сферах, и там, где их не хватает, национальная образовательная система должна усиливать свое воспитательное воздействие и форсированно создавать лидеров.

Методологическая основа исследования.

В настоящем исследовании мы опирались на труды известных в научном сообществе людей, занимающихся проблемой обучения в высшей школе (А.М. Егорычев, А.А. Квитковская, А.Д. Лопуха, Л.В. Мардахаев, Г.Н. Сартан, И.А. Федосеева, С.Н. Фомина, др.), в частности, формированием лидерских качеств у 
студентов (Р.Л. Кричевский, И.В. Никулина, др.), а также специалистов-дидактов, занимающихся проблемами преподавания иностранного языка в вузе (Е.Ю. Варламова, В.И. Уваров, др.) [1; 2; 3; 4; 5; 7; 8; 9; 10].

Постановка проблемы.

Прежде чем говорить о возможностях формирования лидерских качеств у человека любого статуса и социальных ролей, следует четко определить понятие лидерства, которое будет ключевым в данной статье.

Многие ошибочно полагают, что менеджер и лидер представляют собой одно и то же. На самом же деле, между этими двумя социальными ролями, к сожалению, лежит огромная пропасть. Для нашего дальнейшего изыскания будет достаточно понимать, что менеджер или управленец - это человек, который дает указания своим подчиненным и контролирует их выполнение, применяя поощрение или наказание в качестве мотивирующих инструментов. В реальности менеджеры часто очень отдаляются от своего коллектива, более того, становятся недостижимы, ограничиваясь лишь односторонней связью. Часто такое «обособление» приводит к скрытой или явной неприязни сотрудников по отношению к их начальству. Утверждение «власть портит людей» полностью себя оправдывает. Проблема подобного «противостояния» имеет множество негативных последствий как для организации, так и для еe сотрудников, а также в разы сокращает продуктивность труда, что уже грозит коллапсом национального масштаба.

Лидеры же - те люди, которые позволяют удержать организации от развала или же помогают создать новые «здоровые» предприятия, которые приходят на смену «зараженным диктатурой». В отличие от менеджеров, лидеры не диктуют задачи, они предлагают их решение, основываясь на позитивной мотивации сотрудников, воодушевляют последних на творчество и проявление инициативы. Лидеры являются частью коллектива, и вокруг них всегда царит позитивная рабочая атмосфера, сотрудники, ощущая себя значимыми членами единой команды, сознательно стремятся работать качественнее, чтобы не подвести свою команду и лидера.

Исходя из вышесказанного, стратегическая важность формирования лидерских качеств, в частности, у студентов не вызывает сомнений.

Обсуждение результатов исследования.

Анализируя студенческую аудиторию, с которой работает автор, преподавая английский язык на межфакультетской кафедре в неязыковом вузе уже более 13 лет, выявляется факт, что среди всех вместе взятых студентов различных направлений подготовки лишь двое из десяти обладают предрасположенностью или мотивацией к лидерству. Кроме того, мы также отмечаем тревожную тенденцию, что с каждым годом таких студентов становится все меньше в соотношении с общей массой. «Современные» студенты часто уступают своим предшественникам в амбициозности, активности, усердии, сознательности и чувстве ответственности, а также крайне редко осознают свою учебную группу единым целым. Именно поэтому автор предлагает всеми доступными средствами, в том числе и на занятиях по иностранному языку, формировать лидерские качества у современных студентов, ведь, как бы банально это не звучало, за ними будущее, которое мы можем потерять, если не предпримем посильные меры уже сейчас.

Далее в статье автор предлагает рассмотреть возможности преподавателя в плане формирования лидерских качеств у своих студентов на занятиях иностранного языка в неязыковом вузе.

Преподаватели иностранного языка на межфакультетской кафедре неязыкового вуза, на наш взгляд, имеют уникальную возможность одновременно работать со студентами различных направлений подготовки, тем самым оказывая положительное влияние на будущих специалистов в различных сферах деятельности.

Автор предлагает разделить факторы, способствующие формированию лидерских качеств у студентов, на две условные составляющие: 1) личностные качества преподавателя как образца для подражания и 2) виды учебной деятельности актуального формата.

\section{Педагог - лидер команды.}

Для того, чтобы иметь возможность эффективно воздействовать на студентов с целью воспитания в них «добрых» качеств, а также жизненно-необходимых умений и навыком, преподаватель и сами студенты должны адекватно воспринимать статус и формат их взаимоотношений в рамках учебного процесса. «Преподаватель должен видеться студентам не как контролирующая и карающая сила, а как наставник, лидер команды и, в некоторой степени, друг [6]». Студенты, в свою очередь, должны искренне осознавать себя равноправными членами команды и равняться на лидера - преподавателя. Только при таком понимании шаблонной модели «преподаватель - студенты» возможно, на наш взгляд, качественное и ненавязчивое воспитательное воздействие педагога на его подопечных.

Чтобы студенты видели в преподавателе «союзника» или, что еще лучше, достойного подражания лидера команды, педагог должен задействовать все имеющиеся у него знания методики, психологии, риторики, а также искренне, абсолютно искренне, желать и стремиться к воспитанию успешных личностей студентов, верь в успех своей работы и успех своих подопечных. [7, с. 49]

Огромную роль в установлении благоприятных условий для качественного сотрудничества педагога и его подопечных играет умение первого профессионально мотивировать студентов на учебную деятельность, а также умение пролонгировать созданную позитивную рабочую атмосферу и мотивированность на весь срок изучения предмета. Подробнее о важности мотивации студентов и способах ее формирования можно прочесть в 
статье «The problem of motivation of students within the educational process and possible strategies for its solution» [10, c. 63-68].

При этом, если даже сам преподаватель в силу каких-либо личностных особенностей не проявляет лидерских качеств, на наш взгляд, он обязан предлагать студентам учебный контент, способствующий их формированию.

\section{Основные виды учебной деятельности, способствующие формированию лидерских качеств у студентов.}

Рассмотрим ряд наиболее отвечающих задаче формирования лидерских качеств у студентов видов учебной деятельности, представив его в виде не ранжированного по степени важности списка:

Формы работы в ходе выполнения "рутинных» учебных заданий.

Исходя из собственного профессионального опыта автор может с уверенностью утверждать, что воспитание лидерства возможно в самых мелочах учебного процесса, например, когда типовое задание слегка меняет формулировку. Предположим, что студентам была задана на предварительное самостоятельное ознакомление (в виде домашнего задания) статья профильного содержания. Вместо того, чтобы самостоятельно проверить общее понимание и умение ориентироваться в деталях статьи, педагог может номинировать одного из студентов провести проверку (при этом, конечно, полностью контролируя процесс и не допуская возможности ошибки). Подобная временная «передача полномочий» преследует сразу несколько воспитательных целей. Во-первых, принимая во внимание, что студенты видят в педагоге своего лидера и наставника, ответственные за проверку домашнего задания студенты получают возможность почувствовать себя в роли номинального лидера, подражая лидерским поведенческим моделям преподавателя. Во-вторых, студенты получают представление о том, что вести учебный процесс - далеко не простое дело, требующее концентрации, ответственности и других важных качеств личности. Это понимание еще больше способствует уважительному отношению студентов к педагогу и его труду и, в свою очередь, укрепляет воспитательную/наставническую позицию преподавателя в группе. В-третьих, подобное делегирование способствует установлению позитивной рабочей атмосферы, что, как уже говорилось ранее, является одной из ключевых функций лидера.

Групповая работа в ходе проектной деятельности.

Проектная деятельность в группах открывает перед педагогом широкий спектр возможностей научить студентов работе в команде с постоянным или переходящим лидерством. Если проект представляет из себя сложный набор действий, в нем может быть «главный» лидер-организатор и номинальные лидеры, отвечающие за различные аспекты. Вся подготовительная работа должна проходить в общем чате (оптимальный, на наш взгляд, формат современного совместного творчества) с участием преподавателя, помогающего и направляющего лидеров проекта.

Групповая работа в формате глобальной игры.

В очень упрощенном виде глобальная игра представляет собой пролонгированную ролевую игру, способную полностью или частично подменить классический формат ведения занятий. Главной задачей глобальной игры является проецирование максимально приближенной к реальности цепочки рабочих моментов, с которыми выпускники могут столкнуться на пути своего карьерного роста. Особенностью глобальной игры являются переходящие из одного тематического модуля (каждый модуль проецирует реальную рабочую задачу) в другой персонажи, а также полностью замещающая классическую оригинальная система оценки прогресса каждого участника. Типичным примером глобальной игры, состоящей из длинной цепочки модулей, может быть процесс работы компании над новым видом товара, начиная с обсуждения общей концепции будущего продукта и заканчивая его реализацией на рынке.

В процессе игры студенты выступают в роли сотрудников компании и являются ответственными за свой сектор работ. Лидер рабочей группы постоянно меняется по мере того, как участники переходят от одного этапа разработки продукта к другому. Также возможны повышения и понижения в должности, что является одним из итоговых параметров оценки студенческой результативности. Подробнее о технологии глобальной игры можно прочесть в статье «Концепция глобальной игры в обучении студентов иностранному языку» [8, с. 107-115]

Командные межфакультетские студенческие мероприятия творческой направленности.

По схожему принципу строится работа студентов в командах на межфакультетских творческих конкурсах. Особенностью этого формата является возможность студентов работать к команде, состоящей из представителей различных профильных направлений, что позволяет каждому из них «лидировать» в группе в рамках своей профессиональной компетенции. Примером подобных мероприятий может стать межфакультетский студенческий конкурс по созданию товара или услуги для определенного региона. В каждой команде, предположим, есть студент-экономист (отвечает за бизнес план и общий бюджет проекта), студентпсихолог (отвечает за анализ параметров целевой аудитории и консультацию по дизайну), студент-маркетолог (отвечает за разработку имиджа товара, его дизайн и рекламную кампанию). Будучи лидером в рамках своего направления, каждый участник группы понимает, что его успех непосредственно зависит от успеха всей команды и наоборот.

Заключение 
В качестве вывода автор хотел бы еще раз подчеркнуть важность формирования лидерских качеств у современных студентов. Вузы должны с полной ответственностью подойти к решению этой задачи, чтобы не допустить в будущем численное превосходство «просто менеджеров» над лидерами во всех сферах жизнедеятельности нашего общества. На наш взгляд, именно настоящие лидеры смогут компенсировать тот урон, который наносят мировому сообществу постоянные экономические, политические, социальные кризисы. Именно харизматичные лидеры должны встать у основ будущего более совершенного мира.

\section{Список литературы:}

1. Егорычев А.М., Федосеева И.А. Концепция управления системой образования в современном высшем учебном заведении на основе синергетического подхода // Вестник экономической интеграции. - 2012. - № 8 (52). - C. 167-173. URL: https://elibrary.ru/item.asp?id=18726411

2. Квитковская А.А., Шевченко Н.И. Проблемы и пути совершенствования подготовки педагогических кадров // Человеческий капитал. - 2016. - № 5 (89). - C. 25-27. URL: https://elibrary.ru/item.asp?id=26113493

3. Кричевский Р.Л. Психология лидерства. М.: Издательство «Статут», 2007. 541 с.

4. Лопуха Т.Л., Лопуха А.Д. К формированию идеологических основ российского образования // Ученые записки Российского государственного социального университета. - 2015. Т. 14. - № 3 (130). С. 117-126. URL: https://elibrary.ru/item.asp?id=24398032

5. Никулина И.В. Организация учебно-воспитательного процесса в студенческой группе с учетом особенностей лидерства // Профессиональное образование: проблемы, подходы, новации: сб. науч. статей; под ред. Т.И. Рудневой. Самара: Изд-во СГУ, 2014. С. 65-74.

6. Полянская Н.M. Роль преподавателя в повышении качества образовательного процесса в высшем учебном заведении // Интернет-журнал «Мир науки» 2015 №3 http://mir-nauki.com/PDF/48PDMN315.pdf (доступ свободный). Загл. с экрана. Яз. рус., англ. (дата обращения: 17 февраля 2021)

7. Уваров В.И. Воспитательная составляющая учебного процесса как способ дополнительной мотивации студентов к самосовершенствованию и саморазвитию // The scientific heritage (Budapest, Hungary). — 2019. T. 3, № 40. - C. 48-50. ISSN 9215-0365

8. Уваров В.И. Концепция глобальной игры в обучении студентов иностранному языку // Вестник РГГУ. Серия «Психология. Педагогика. Образование». 2019. - № 3. С. 107-115. URL: https://elibrary.ru/item.asp?id=41125317

9. Федосеева И.А. К вопросу о качестве высшего образования в современном российском обществе // ЦИТИСЭ. 2016. - № 3 (7). - С. 26. URL: https://elibrary.ru/item.asp?id=26398867

10. Uvarov VI. The problem of motivation of students within the educational process and possible strategies for its solution // Materials of the International Conference "Scientific research of the SCO countries: synergy and integration" - Reports in English. Part 3 (August 31, 2019. Beijing, PRC) - pp. 63-68. ISBN 978-5-905695-51-3

\section{References:}

1. Egorychev A.M., Fedoseeva I.A. Koncepcija upravlenija sistemoj obrazovanija v sovremennom vysshem uchebnom zavedenii na osnove sinergeticheskogo podhoda // Vestnik jekonomicheskoj integracii. - 2012. - № 8 (52). S. 167-173. URL: https://elibrary.ru/item.asp?id=18726411

2. Kvitkovskaja A.A., Shevchenko N.I. Problemy i puti sovershenstvovanija podgotovki pedagogicheskih kadrov // Chelovecheskij kapital. - 2016. - № 5 (89). - S. 25-27. URL: https://elibrary.ru/item.asp?id=26113493

3. Krichevskij R.L. Psihologija liderstva. M.: Izdatel'stvo «Statut», 2007. 541 s.

4. Lopuha T.L., Lopuha A.D. K formirovaniju ideologicheskih osnov rossijskogo obrazovanija // Uchenye zapiski Rossijskogo gosudarstvennogo social'nogo universiteta. - 2015. T. 14. - № 3 (130). S. 117-126. URL: https://elibrary.ru/item.asp?id=24398032

5. Nikulina I.V. Organizacija uchebno-vospitatel'nogo processa v studencheskoj gruppe s uchetom osobennostej liderstva // Professional'noe obrazovanie: problemy, podhody, novacii: sb. nauch. statej; pod red. T.I. Rudnevoj. Samara: Izd-vo SGU, 2014. S. 65-74.

6. Poljanskaja N.M. Rol' prepodavatelja v povyshenii kachestva obrazovatel'nogo processa v vysshem uchebnom zavedenii // Internet-zhurnal «Mir nauki» 2015 №3 http://mir-nauki.com/PDF/48PDMN315.pdf (dostup svobodnyj). Zagl. s jekrana. Jaz. rus., angl. (data obrashhenija: 17 fevralja 2021)

7. Uvarov V.I. Vospitatel'naja sostavljajushhaja uchebnogo processa kak sposob dopolnitel'noj motivacii studentov $\mathrm{k}$ samosovershenstvovaniju i samorazvitiju // The scientific heritage (Budapest, Hungary). — 2019. — T. 3, № 40. — S. 48-50. ISSN 9215-0365

8. Uvarov V.I. Koncepcija global'noj igry v obuchenii studentov inostrannomu jazyku // Vestnik RGGU. Serija «Psihologija. Pedagogika. Obrazovanie». 2019. - № 3. S. 107-115. URL: https://elibrary.ru/item.asp?id=41125317

9. Fedoseeva I.A. K voprosu o kachestve vysshego obrazovanija v sovremennom rossijskom obshhestve // CITISJe. 2016. - № 3 (7). - S. 26. URL: https://elibrary.ru/item.asp?id=26398867 
10. Uvarov VI. The problem of motivation of students within the educational process and possible strategies for its solution // Materials of the International Conference "Scientific research of the SCO countries: synergy and integration" - Reports in English. Part 3 (August 31, 2019. Beijing, PRC) - rr. 63-68. ISBN 978-5-905695-51-3 